\title{
Supporting Shop Floor Workers with a Multimedia Task- oriented Information System
}

\author{
Benny Tjahjono* \\ Department of Manufacturing, School of Applied Sciences, Cranfield University, \\ Cranfield, Bedford MK43 0AL, UK
}

\begin{abstract}
This paper reports the work carried out as part of an industrial research project sponsored by a major telecommunication industry based in the UK. The main aim of the research was to investigate the extent to which a multimedia-based information system, developed for shop floor workers, has contributed to the increased efficiency and productivity of manufacturing operations. To achieve this, the work has focused on the design and execution of the evaluation of the system. Due to the fact that the direct impact of the implementation of the information system developed was difficult to demonstrate, it was decided to adopt the system usage as a surrogate of the system $\mathbb{S}$ success and the user acceptance of the system was evaluated using both the Technology Acceptance Model and the Task-Technology Fit model.
\end{abstract}

Keywords: Standardised Work, Information Support System, Usability, Technology Acceptance Model, Task-Technology Fit

*Corresponding author:

Building 50, College Road, Cranfield University

Cranfield, Bedford MK43 0AL, UK

Tel.: +44 1234750111 x5453; Fax: +44 1234751172 .

E-mail address: b.tjahjono@cranfield.ac.uk 


\section{Introduction}

Future success for manufacturing industries in developed countries is believed to depend on their ability to move up the value chain. In manufacturing systems, moving up the value chain is often associated with increased efficiency of operations as a result of elimination of waste, i.e. those that are not contributing to the value of products and services, for example unnecessary rework of defective products due to inconsistency and variation of production processes. To this end, both Toyota Production Systems and, lately, Lean Manufacturing emphasise standardisation as a means to address the issue.

Increased efficiency is also often attributed by shifting production facilities to low wage countries and rationalisation of resources through automation, making many labour intensive tasks redundant. The increased demand for multi-skilled and autonomous workers, coupled with the requirement to adhere to the work standard, has put more pressure on provision of continual training and skill development. In this respect, provision of an extra function in the form of an information support system is believed to be necessary to support job performance.

The main purpose of the research described in this paper is to investigate the extent to which an information support system developed to support shop floor workers has contributed to the increased efficiency and productivity. One common way to do this is to compare the performances (e.g. quality and speed of task execution) prior and post system implementation, and then to quantify the benefits. However, due to the difficulty in identifying any improvement as a direct consequence of the system implementation 
(and not as a result of other continuous improvement initiatives), an objective evaluation of the information system is almost impossible to conduct.

For this reason and as suggested in the literature, system usage has been adopted as a surrogate measure of the success and an indication of the likelihood of whether the system will impact the task performance. Consequently, the evaluation has been focused on assessing the attributes of the system usage following the Technology Acceptance Model and the Task-Technology Fit model.

The paper first sets out the background of the research from the industrial perspective which covers the industrial problems and the relevance of the Information Support System to the sponsoring company, upon which the research aim and methodology are proposed. The main body of this paper focuses on the design and execution of the system $₫$ evaluation. Not only have the outcomes of the evaluation been used as a basis for further improvement to the system, but more importantly, they have helped the company understand the various factors that suggest whether the system will be likely to contribute to increased efficiency of their manufacturing operations. In addition, from a theoretical perspective, the paper also enhances our understanding of the relevance of the IT systems to skill development and training of shop floor personnel in today $s$ manufacturing organisations.

\section{Background}

\subsection{The Need for an Information Support}

Manufacturers in the developed countries continue to face a fierce competition from newly emerged, low cost economies around the world. Increased capital flow, reduction in transportation cost and advancement in information and communication technologies 
have shifted away many of production facilities from the developed countries to Asia, Far East and Eastern Europe. With the relatively high wage rates in the developed countries, it is unlikely that manufacturers in these countries will be able to compete on the basis of mass-produced, low-value products where labour costs are a significant component that determines the price. Future success is therefore believed to depend on the ability to move up the value chain and to turn the increased openness of world market into the competitive advantages. In production and operations of manufacturing systems, moving up the value chain implies increased value of products (and services) as a result from elimination of non-value added activities (or also known as waste $)$ and increased efficiency.

Waste elimination is central within the Toyota Production System [1] and Lean Manufacturing [2]. Both of them emphasise on standardisation as one of the means of reducing wastes, particularly those that are caused by defect and rework [3]. In this respect, standardised procedure reduces variation because, providing the standard is adhered, the work will be performed the same way each time. Typical standardised work includes quality documentation, e.g. Standard Operating Procedures (SOP) and Work Instructions (WI), as well as the relatively less formal ones, e.g. single point lessons $\square$ and other visual instructions.

Increased efficiency is often attributed by automation and shrinkage of production facilities through outsourcing which gives a dramatic impact on human resources. With rationalisation of production resources, a large number of workers exemplified in Taylorism and mass production systems, has now been replaced by a relatively small number of workers. The emphasis is now placed upon autonomous workforce who is 
able to work with less scrutiny, skilful on different sets of job and willing to accept more responsibilities [4].

An efficient production system also requires coordination between different subsystems within a manufacturing organisation including the technical systems (e.g. machines, materials and processes) and the social organisation (e.g. people and their skills and competencies). The combination between the two is also known as a sociotechnical system. Kasvi et al [19], quoting the theory of socio-technical design by Emery [20], stated that effective and flexible socio-technical systems can be achieved if they have a certain amount of overcapacity or redundancy, not by redundancy of parts (i.e. having extra people), but instead by redundancy of functions to those parts. In this respect, redundancy of functions is achieved through equipping people with extra skills and competencies, through continual training and skill development as well as the provision of information systems to support the job, akin to the Performance Support Systems [5].

\subsection{The Industrial Problems}

The research described in this paper is funded by a global manufacturer and a provider of integrated telecommunications solutions. The manufacturing process involves the production, assembly and testing of base transceiver stations, one of the main equipment in the cellular telecommunication networks. The manufacturing facility consists of a number of assembly lines, starting from the printed circuit boards (PCB) components mountings and ending in the systems test area. The company is obliged by TL9000 standard to demonstrate the conformance in supplying high quality telecommunication products. According to this standard, the products have to pass a number of tests, carried out in a computerised test station shown in Figure 1. 


\section{[Insert Figure 1 here]}

Although the majority of the test procedures are under the control of the test software, the overall test process remains labour-intensive. The test software prompts the test operator with instructions to connect and disconnect the peripherals to the test station, emulating the communication functionality in a cellular network. The successful completion of the test process, therefore, not only depends on the accuracy of the test equipment, but also on the competency of the test personnel to carry out the test procedure.

The need for multi-skilled test operators means that training has to be given more frequently than usual. Many inexperienced test operators have to be trained by qualified engineers on a face-to-face basis. With a large variety yet relatively small volume of products, however, this type of training method becomes inefficient and costly, as it may cause a greater workload for the engineers because the demand for training is growing particularly during the new product introduction.

However, assuming the availability of dedicated resources to deliver training materials, the amount of information delivered through a conventional, face-to-face training may be influenced by the social environment and other human factors. This results in variability and inconsistency of the knowledge received by the trainees because different trainers sometimes deliver the same training material using different methods.

Despite the widespread use of computers in industry, $80 \%$ of today $s$ technical documents, for example the Standard Operating Procedures (SOPs) for assembly and maintenance, still exist in paper-based format [6]. These documents are written mostly using text that only provide limited $\mathbb{k n n o w}$-how $\square$ on manufacturing processes. In 
addition, SOPs typically have a lot of cross-references to other documents. Reading a document with persistent cross-references is obviously prone to error.

The complexity of the products, together with the advanced technology involved, has produced abundant information that is generally less structured and hence unsuitable for all levels of expertise. This information is available only during the training programme, after which the operators will only have limited access to more detail information. Even if this information was available, it needs to be located as and when required, making it more difficult to obtain the required task-related information in a timely manner.

Due to the pace of developments in electronic fabrication technology, product leadtimes become shorter and this has put more pressure on product testing. As product testing is the last process on the assembly line, a fast and reliable test process is critical to avoid blocking the line and causing late or unreliable delivery.

If the company relies upon standardised procedures to maintain the consistency, and hence the quality and productivity of the testing process, then they need a support system that provides extra functions (redundancy of functions) to the test operators. Ideally, the system should provide accurate, up to date information, accessible ondemand directly from the point where the task is carried out and is delivered consistently.

\subsection{The Information System Developed}

As part of its strategic improvement programme, the company has initiated the development of an interactive, multimedia-based Information Support System capable of meeting all the abovementioned requirements to support the tasks in hand, in this case the product testing. It was envisaged that this would enable the provision of a 
comprehensive learning environment that could guide operators to carry out the test process effectively and efficiently with either minimal or no extra training.

To this end, the Information Support System has been developed to serve two purposes: (1) as a training tool and (2) as a task support or memory aid. As a training tool, it can be used to simulate how the test procedure is carried out thus allowing the trainee operators to carry out test procedures as if they were working in a real environment. The simulated testing environment itself consists of the test software, the base station, the components and the test station (Figure 2). As a task support, the system provides quick access to Standard Operating Procedures (SOPs) for systems test delivered using multimedia format.

\section{[Insert Figure 2 here]}

As mentioned earlier, testing a base station is a combination of manual and automated tasks that are controlled by the test software. The animated test software within the Information Support System also follows exactly the same test sequence and prompts exactly the same commands or messages to the operators to perform a number of actions. Providing that the users performed the correct action at the correct time, the system would proceed sequentially to the next step. As the users became more familiar with the test procedure, they might jump from one step to another in a non-linear fashion. In this way, they did not necessarily need go through the whole sequence of the test procedure.

To simulate the test software, screenshots of each stage of the test process were collected. The series of screenshots were then converted into animations that simulated particular instances of the test software. Each animation controlled the logic of the 
system. It judges the action taken by a user while using a virtual tool, for example positioning a virtual tool or clicking on the correct switch. Consequently, the virtual tool acts as the trigger of every event affecting the display of the screenshot of the test software, thus controlling the logic to the next step. Various computer mouse interactions are used to simulate these actions. Turning the switch on is simulated using a click of the mouse and placing/replacing components is simulated using click and $\operatorname{drag}$.

Digital video clips, also known as how-to-do video, are given to illustrate how the step is actually carried out in the real testing environment. This can be used when the system is operated online, in conjunction with the actual testing process.

\section{Research aim and methodology}

The main purpose of the research is to investigate the extent to which the Multimediabased Information Support System has contributed to the increased efficiency and productivity of the test process. To this end, one approach to evaluation of the system would have been to record the time required (speed) to carry out test process and how this process was carried out (quality) before and after the system was introduced. This would certainly give an indication for any changes in efficiency and effectiveness of the test process. Although it would have been a cost-effective way to compare performance before and after systems installation as well as comparing the performance of the test process with the information systems to that of the test process without, this type of comparison was difficult to accomplish. The main reason was because, at that time, the sponsoring company was pursuing several continuous improvement projects besides the introduction of the Information Support System and consequently it might have been 
difficult to clearly identify any improvement that was a direct consequence of its introduction.

Furthermore, despite a vast amount of work in the area of Management Information Systems, the direct impact from implementation of Information Systems to the organisational performance is difficult to identify [7]. Consequently, many of the criteria to evaluate Information Systems implementation (including the system developed in this research) obtained from the literature suggested system usage as the surrogate of the success measures and hence the primary indication of success (e.g. [7], [8], [9]). They all argued that the system $s$ usage is somehow a pre-requisite that needs to be fulfilled before the impact and task performance can be measured.

Consequently, during the development of the Information Support System, the evaluation has been focused on investigating whether or not the users will use and will continue to use it. Achieving this aim requires the following objectives to be accomplished:

1. Design a protocol upon which the evaluation will be based,

2. Execute the protocol involving the potential users of the system, and

3. Analyse the results of the evaluation.

The sponsoring company has provided an avenue for executing the research programme through the development and deployment of the system on the shop floor. In addition, the company also allowed the researcher to focus the inquiry on a specific situation through observation of real industrial problems and to experiment with a number of 
factors in a more flexible way. For this reason, the methodology adopted in this research has been case study based [10].

\section{Design and Execution of the Evaluation}

The case study research allows a combination of quantitative and qualitative approaches. The quantitative approach is likely to produce quantified and, if possible, generalised conclusions drawn from the relationships of one set of facts to another [11]. The investigation will therefore be carried out using a questionnaire to capture the success measures in terms of system usage. The qualitative approach, on the other hand, deals with insight gathered from individuals $\square$ perceptions of the subject being observed [11]. The advantages of combining the two approaches together are that one approach can be used to check the findings from the other, and that the approaches can complement each other should one approach be hard or impossible to achieve [12]. Consequently, it was decided to employ both quantitative and qualitative evaluations of the Information Support System developed for the sponsoring company.

For the simplicity reason, the Information Support System developed and evaluated in this research will be called the program $\square$ hereafter.

\subsection{Qualitative Evaluation}

The qualitative evaluation mainly aims to accommodate feedback and suggestions from potential users of the program, thereby can be used as a basis of continuous improvement. As with other qualitative evaluation involving interview and working with users, it is important that the characteristics of the potential users are well represented by the subjects of the evaluation. 
Each feedback session was designed to start with a short demonstration of the program. After the demonstration, they were asked to interact with it and were asked to carry out part of the system test process using the program. During this session, the subjects were assured that the researcher was evaluating the program, not their performance. The researcher was mindful that if they were unable to easily carry out the task using the program, then it could mean there were issues with the program.

To close the session, they were interviewed in order to accommodate their suggestions for improving both functionality and user friendliness of the program. The questions asked were open-ended in nature, allowing the interview to be adjusted depending on comments or observations which could be relevant for the evaluation but had not been accounted for in the design of the questions [13]. The questions asked were:

1. What do you like and dislike about the program?

2. What would you change?

3. What is important to you when testing a base station, and what is not well simulated?

4. Would you recommend the program to your colleagues?

\subsection{Quantitative Evaluation}

Literature review in the area of Management Information Systems (MIS) (e.g. [7], [8], [9], [14]) and Human Computer Interaction (HCI) (e.g. [15], [16], [17]) has indicated the two most commonly used models to quantitatively measure the usage of the program, namely the Technology Acceptance Model (TAM) and the Task-Technology Fit (TTF). 
The Technology Acceptance Model (TAM) provides an explanation of the determinants of user acceptance of an information system [8]. The model postulates that the use of an information system is fundamentally determined by the behavioural intentions to use the system (BI), i.e. prospective users $\square$ decision to accept or to reject the system. BI is jointly determined by two other constructs: perceived ease of use (EOU), which is the degree to which the prospective users expect the system to be free from effort, and perceived usefulness $(\mathrm{U})$, which is the prospective users $\square$ subjective expectation that using a specific system will increase their job performance (including effectiveness, productivity and efficiency).

The Task-Technology Fit (TTF) postulates that information systems will be used if, and only if, the functions available to the user fit the tasks of the user [7]. Consequently, the system that does not offer sufficient advantage will not be used. The TTF model provides a theoretical foundation for investigating factors that affect the degree of fit between task characteristics and technology characteristics or IT system functionalities.

As both models have distinctive features (TAM measures user acceptance and TTF measures the degree of fit between the program and the task), it was decided to employ both TAM and TTF. A questionnaire was then developed as a research instrument based on the two models.

The questionnaire was structured into three parts. The first part collected background information about the subjects, including task familiarity or task characteristic. In this respect, the subjects are required to express their agreement to each of the statements using a 7-point Likert scale.

shows the questions used to capture this information. 


\section{[Insert Table 1 here]}

The second part collected the perceptions about the program, using the research instrument developed based upon TAM constructs (Table 2). The constructs used were perceived Ease Of Use (EOU), perceived Usefulness (U) and Intention to Use the system (IU). As with the first part, the items for each construct were also using a 7-point Likert scale.

\section{[Insert Table 2 here]}

The third part of the questionnaire aimed to study the degree of fit between the program and the tasks it supports (in this case systems test), using the 12 TTF constructs devised by Goodhue [18]. In his study, he argued that these constructs apply to any IT system, including hardware, software and data. However, the original TTF instruments in Goodhue [18] seem too specific to the information systems and services used to test it and, as such, not all constructs were deemed appropriate for the evaluation of the program.

The four TTF constructs depicted in Table 3 were believed to be irrelevant in the context of the evaluation of the program. In theory, these constructs should not be an issue because the data are already available and linked into the program. Consequently, these constructs were dropped.

\section{[Insert Table 3 here]}

Furthermore, three more constructs were omitted from the remaining 8 . These were presentation, ease of use and level of detail. The first two were not used because of the presence of the TAM construct to measure ease of use of the program, which includes 
the presentation. The last one was dropped because the level of detail of the program has been set to cover the systems test, i.e. simulating the entire process of testing a base station, thereby evaluating the level of detail was deemed unnecessary.

The remaining five TTF constructs and the corresponding questions used in the evaluation are shown in

Table 4 and

Table 5 respectively.

[Insert Table 4 and Table 5 here]

\section{Analysis of the Findings}

\subsection{Qualitative Evaluation}

Five one-on-one feedback sessions were attended by five prospective users (called subjects hereafter). Two of these were experienced test operators and the remainder were operators from other areas who were not familiar with the systems test procedure. The latter represents novice operators ${ }^{1}$.

The findings are summarised below:

1. Preference. The subjects liked the idea of using a computer to learn their job. They believed that learning by doing $\square$ was the most effective way to familiarise themselves with their daily job. The program has facilitated this by providing useful and more interesting learning materials than the conventional method. Nevertheless, as the technology was still new, there was a concern that the program could be too

\footnotetext{
${ }^{1}$ The company considers those operators who have less than 6 months working experience as novice.
} 
intense for subjects who were less computer literate, as learning to use the program might take longer than learning to do their job.

2. Changes required. The majority of the subjects liked to have seen more digital video clips incorporated into the program. They also preferred a larger screen and hence the higher screen resolution, so that the screenshots of the test program could be positioned properly. Finally, they expected a quicker download time while maintaining a reasonably good quality of the video clips.

3. Important features. Since the program is intended to be self-explanatory, it was suggested that novice users would require introductory sections describing the testing environment, tools and peripherals required. In addition, since not all manual operations could be simulated perfectly using mouse actions, for example turning the potentiometer anti-clockwise, they preferred static pictures to illustrate these.

4. Recommendations. The subjects would recommend the program to their colleagues, providing that certain changes they had requested were made.

These suggestions were incorporated into subsequent versions of the program.

\subsection{Quantitative Evaluation}

This evaluation aimed to collect empirical evidence as to whether the subjects of the evaluation could use the program and whether they would continue to use it in the future. The subjects chosen for this evaluation were the systems test operators. As the majority of the subjects were experienced operators, once again, it was decided to include operators from other areas of the assembly lines in the evaluation study, to represent trainee operators who were not familiar with either the systems test process or the product to be tested. 
Apart from participating in the feedback session, none of the subjects had used the program before, neither had they seen the questionnaire prior to the evaluation. A total of 17 responses were collected but only 16 of them were used in data analysis because many of the questions were left blank by one subject.

\subsubsection{Profile of the Subjects}

As mentioned earlier, the first part of the questionnaire collected the background of the subjects, and this was used to build the profile of the subjects in terms of working experience and their familiarity of the tasks. Figure 3 indicates that around one-third of the subjects were the novice test operators and subjects from other departments; and the remaining were experienced operators who had been working in the test area for more than 7 months.

\section{[Insert Figure 3 here]}

Figure 3 also shows the sample profile of task familiarity. The mean value of the task familiarity for the novice operators was 2.5 out of 7, indicating that they were not familiar with either the systems test or the products (base stations). Furthermore, the mean value of task familiarity for the experienced operators was 6.3 out of 7 confirming that they were familiar with the test procedures. Later on, these will be used to investigate whether there is a correlation between task familiarity and other constructs.

\subsubsection{Users Perception of the Program}

Table 6 shows the indices of the TAM and TTF constructs collected by the questionnaire. For each subject group (novice and experienced Operators), the EOU1, EOU2, EOU3 and EOU4 were correlated against each other. Because they are 
positively correlated, the EOU index was calculated as the mean value of the EOU. This was repeated for the other three constructs to obtain the indices of U, TTF and IU.

The subjects perceived the program as easy to use and useful as indicated by the high mean values of both EOU and U. They also indicated the mean value of perceived TTF (measuring the degree of fit between the program and the task it supports) as moderately high. The mean of IU was also high, showing their acceptance of the program.

\section{[Insert Table 6 here]}

\subsubsection{Impact of Task Familiarity to Acceptance of the Program}

One may argue that the subjects $\square$ perceived ease of use and usefulness were because they are already familiar with the tasks. For this reason, it was decided to investigate this further. For each group, task familiarity was correlated against perceived ease of use (EOU) and perceived usefulness (U) (Figure 4).

For novice operators, the graph shows no correlation between task familiarity and perceived ease of use (EOU). This means the ease of use of the program did not depend on task familiarity. For the experienced operators, there was a positive correlation between task familiarity and perceived ease of use (EOU). This result was actually expected. As the subjects had been familiar with their tasks, they were able to predict how the program would behave and respond to their interactions.

\section{[Insert Figure 4 here]}

Although both novice and experienced operators perceived the program as useful irrespective of their background experience (as 
Table 6 shows), there is no correlation between task familiarity and perceived usefulness (U) (Figure 5). This result was somewhat unexpected because, in theory, experience operators should have been able to judge whether the program was useful or would be useful in the future.

\section{[Insert Figure 5 here]}

\subsubsection{Relationships between TTF and Acceptance of the Program}

Another analysis was undertaken to investigate whether the degree of fit between the program and the task affects the acceptance of the program. This was carried out by correlating the Task-Technology Fit (TTF) to perceived ease of use (EOU) and perceived usefulness $(\mathrm{U})$ of the program.

Figure 6 shows Task-Technology Fit (TTF) is positively correlated to both perceived ease of use (EOU) and perceived usefulness (U), although the correlations on perceived usefulness $(\mathrm{U})$ in both novice and experienced operators are slightly more significant than that on perceived ease of use (EOU) as illustrated in graph (b). This suggests that the higher the degree of fit between the program and the tasks, the greater the likelihood that the users will accept the program.

\section{[Insert Figure 6 here]}

\subsubsection{Relationships between TAM constructs}

The final analysis was conducted to better understand the relationships between the constructs as postulated in TAM model. In the case of novice operators, perceived ease of use (EOU) has positive and more significant effect to the Intention to Use. This is perhaps due to the fact that they are unfamiliar with the task thereby they value ease of use more than usefulness. On the other hand, experienced operators deemed usefulness 
more important than ease of use. This was indicated by the stronger, positive correlation between usefulness and Intention to Use the program than that between ease of use and Intention to Use. Similarly, the perceived ease of use (EOU) on both groups is positively correlated to the Intention to Use (IU) as shown in Figure 7 graph (c).

\section{[Insert Figure 7 here]}

\section{Discussion and conclusions}

The main part of this paper has discussed the evaluation of the Information Support System developed for the case company. A number of assessments involving current and potential users have been carried out to investigate whether the system actually impacts on productivity and efficiency of the test process, and has subsequently been used as a basis for further improvement to the system.

Although it is not possible to fully answer the research question, the research has highlighted various factors that will give an early indication of the likelihood that the system will meet the above requirement. The research has also suggested that the users will use and continually use the system only if the system is easy to use, useful, and above all, its functionalities fit the tasks it supports. This is in line with many of the theories postulating that the organisational impact can only be objectively measured if the system is actually used.

Although the statistical approach is often used to analyse the causal relationship between two variables, for practical reasons, the use of a graphical method to illustrate this correlation is preferable. In the context of industry-based research (such as the one described in this paper), for example, demonstrating that there is a correlation between 
task technology fit and usefulness is sufficient to explain such phenomena, while the strength of this correlation is less important.

As with other survey research, the sample size is always an interesting point to debate.

To this end, this research was somehow limited by the relatively small sample size.

However, at the time the evaluation was conducted, there were only 25 test operators in total and it could be argued that the sample has represented the entire population of the subjects.

Despite the limitations, the company believes that the outcome of the research, to a large extent, has a positive impact in contributing to the achievement of the business goals, which include:

- Better use of resources. The time the engineers spend in training new operators, as well as in assisting the experienced ones, will be considerably reduced. The trainee operators can now learn the test operations on a computer without occupying any test equipment. Once they gain the basic knowledge, they can continue with on the job training. This will consequently minimise the non-value added activities in terms of human resources and the equipment.

- On-demand information and training delivery. Information related to the test procedure can now be obtained on-demand because the SOPs and training are now combined into one medium (in the form of an interactive computer software package). In addition, operators can confidently perform the tasks alone, with minimal support from others. 
- Consistency of information in information delivery. As the Information Support System consistently delivers training and information to the trainees, it can eliminate variation in training delivery.

- $\quad$ Time and hence cost reduction. For companies whose manufacturing facilities are located worldwide, the system allows substantial reduction of travel costs as trainees are not needed to attend on-the-job training because some basic training can be done on a computer.

The Information Support System developed during the research project has been expanded across other areas within the manufacturing facilities both as a computeraided training tool and as an interactive task support system. Furthermore, its structure as a knowledge repository lends itself to growth and adaptation as the company $\mathrm{s}$ product range and manufacturing processes progress through time.

From a theoretical point of view, the research has attempted to explain the extent to which the Information Support System has contributed to improved efficiency and productivity of manufacturing systems. The research also enhances our understanding of the significance of IT systems to continual skill development and training of shop floor personnel, a vital catalyst to increased value-added products/services and competitiveness of today $₫ \mathrm{~s}$ manufacturing organisations.

\section{References}

[1]. Ohno, T. (1988). Toyota Production System: Beyond Large-Scale Production, Productivity Press

[2]. Womack, J., Jones, D. and Roos, D. (1991). The Machine That Changed the World: The Story of Lean Production, Harper Perennial

[3]. Liker, J. and Meier, D. (2005). The Toyota Way Fieldbook, McGraw-Hill 
[4]. Frieling, E., Freiboth, M., Henniges, D., and Saager, C. (1997). Effects of team work on the working conditions of short cycled track work: A case study from the European automobile industry, International Journal of Industrial Ergonomics, 20, pp. $371-388$

[5]. Gery, G. (1991). Electronic Performance Support System: How and why to remake the workplace through the strategic application of technology, Weingarten Publications

[6]. Lundeen, G. (2000). Paper and digital document media in an e-business world, In: Downey, C., Marks, E.A., LCHeureux, R., Bragg, S. and Imhoff, C. (Eds), Manufacturing Leadership through the Extended Enterprise (London: Technology Publishing Ltd), pp. 39-42

[7]. Goodhue, D. L. (1995). Understanding User Evaluations of Information Systems, Management Science, Vol. 41, No. 12, pp. 1827-1844

[8]. Davis, F. D. (1989). Perceived Usefulness, Perceived Ease of Use, and User Acceptance of Information Technology, MIS Quarterly, September, pp. 319-339

[9]. DeLone, W. H. and McLean, E. R. (1992). Information systems success: the quest for the dependent variable, Information systems research, Vol. 3, No. 1, pp. 60-95

[10]. Yin, R. K., (1994). Case Study Research $\square$ Design and Methods, Sage Publications

[11]. Bell, J. (1987). Doing Your Research Project A Guide for First-Time Researchers in Education and Social Science, 2nd Ed., Open University Press

[12]. Bryman, A. (1989). Research Methods and Organization Studies, Routledge, Taylor and Francis Group

[13]. Robson, C. (1993). Real World Research: A Resource for Social Scientist and Practitioner Researcher, Blackwell Publishers

[14]. Lucas, H. C. Jr. (1978). Empirical Evidence for a Descriptive Model of Implementation, MIS Quarterly, Vol. 2, No. 2, pp. 27-42

[15]. Nielsen, J. (1995). Multimedia and Hypertext: The Internet and Beyond, Academic Press

[16]. Holzinger, A. (2005). Usability Engineering Methods for Software Developers, Communications of the ACM, Vol. 48, No. 1, pp. 71-74

[17]. Hornbaek, K. (2006). Current Practice in Measuring Usability: Challenges to Usability Studies and Research, International Journal of Human-Computer Studies, Vol. 64, No. 2, pp. 79-102

[18]. Goodhue, D. L. (1998). Development and Measurement Validity of a TaskTechnology Fit Instrument for User Evaluations of Information Systems, Decision Sciences, Vol. 29, No. 1, pp. 105-138

[19]. Kasvi, J. J. J., Vartiainen, M., Pulkkis, A., and Nieminen, M. (2000). The Role of Information Support Systems in the Joint Optimization of Work Systems, Human Factors and Ergonomics in Manufacturing, Vol. 10, No. 2, pp. 193-221 
[20]. Emery, F. (1993). The second design principle $\square$ participation and the democratization of work. In E. Trist \& H. Murray (Eds.), The social engagement of social science, A Tavistock Anthology: Vol. 2. The socio-technical perspective.

Philadelphia: University of Pennsylvania Press 


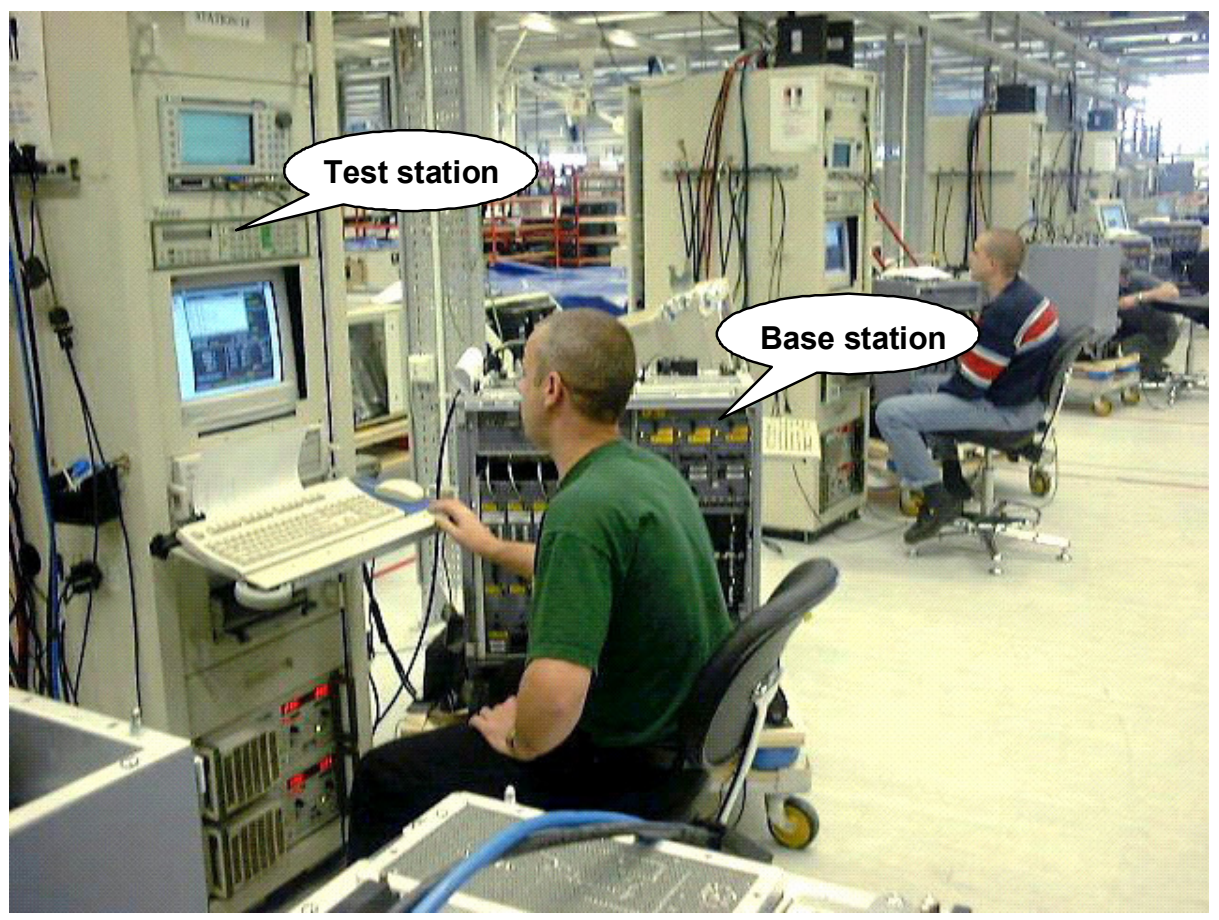

Figure $1 \square$ Systems test area

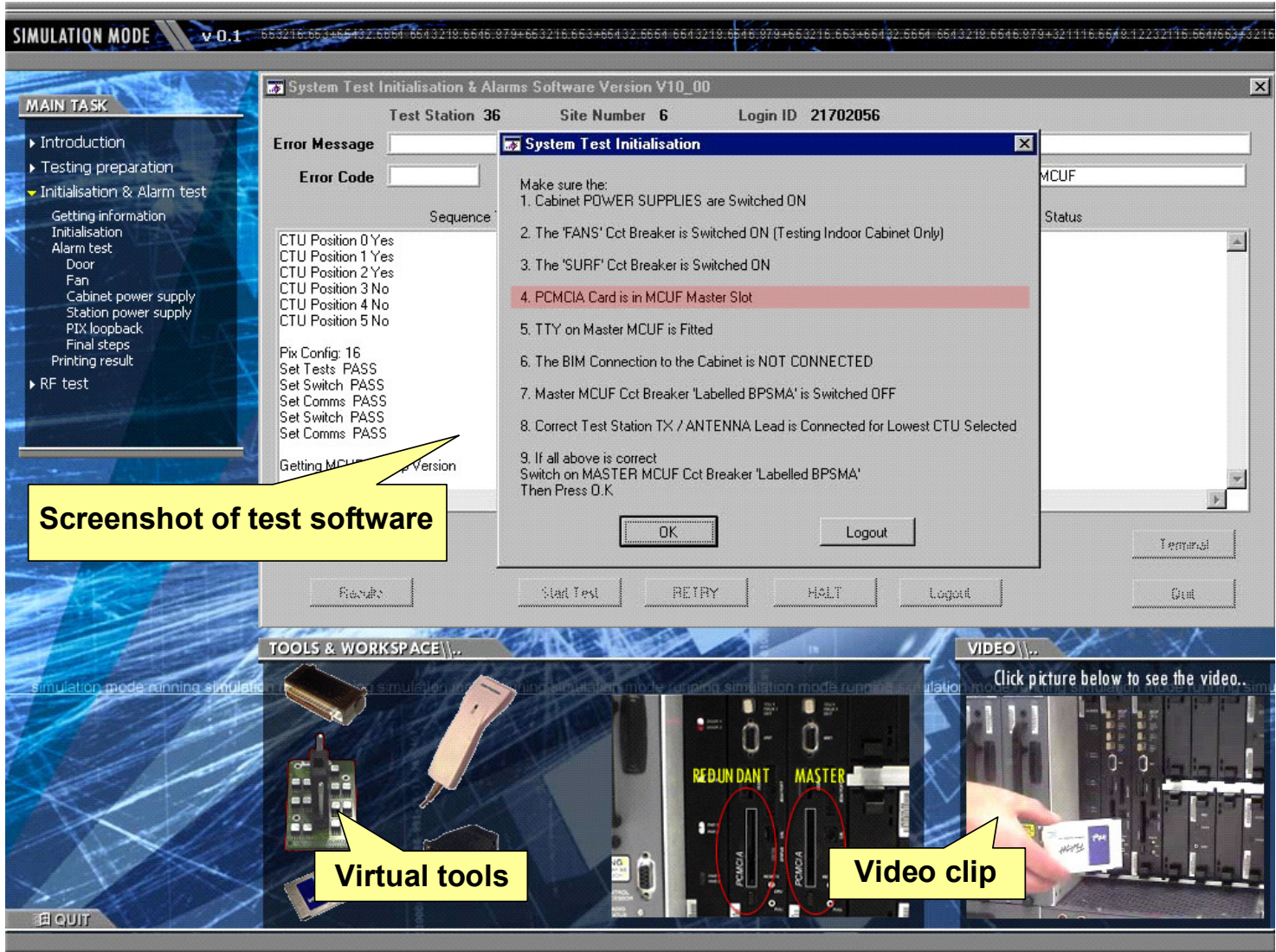

Figure $2 \square$ The Multimedia-based Information Support System 

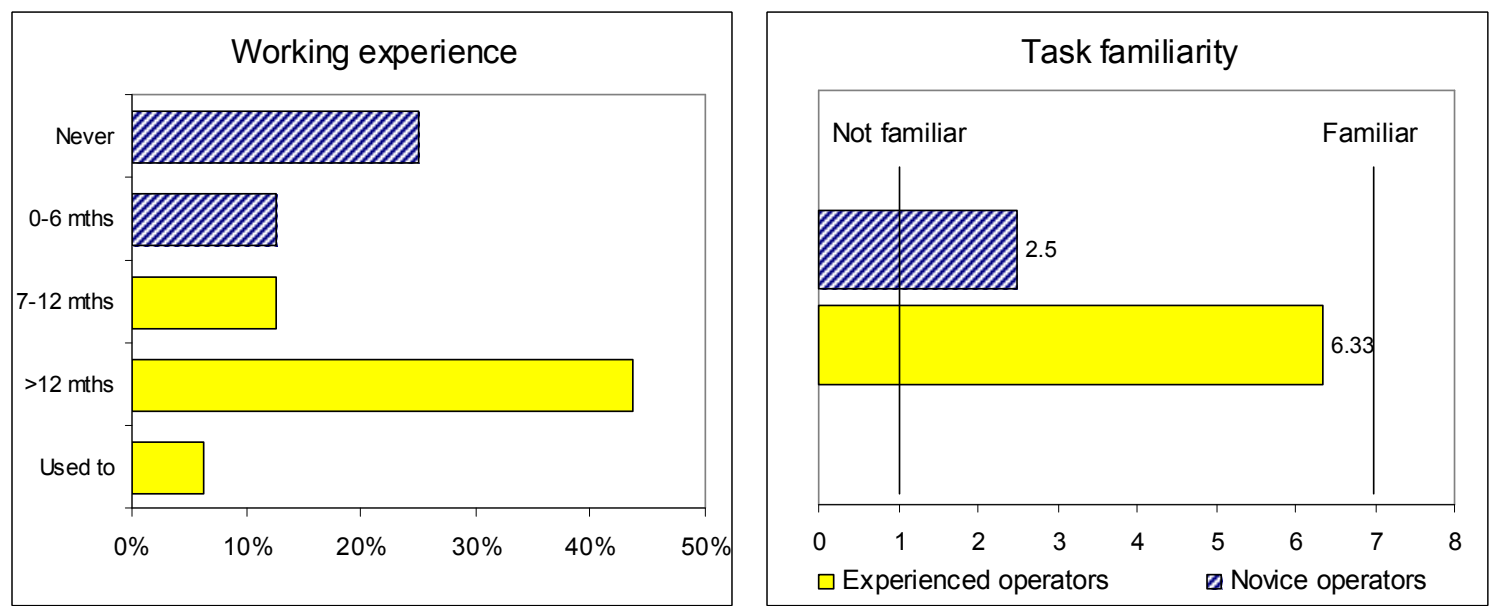

Figure $3 \square$ Sample profile: working experience and task familiarity
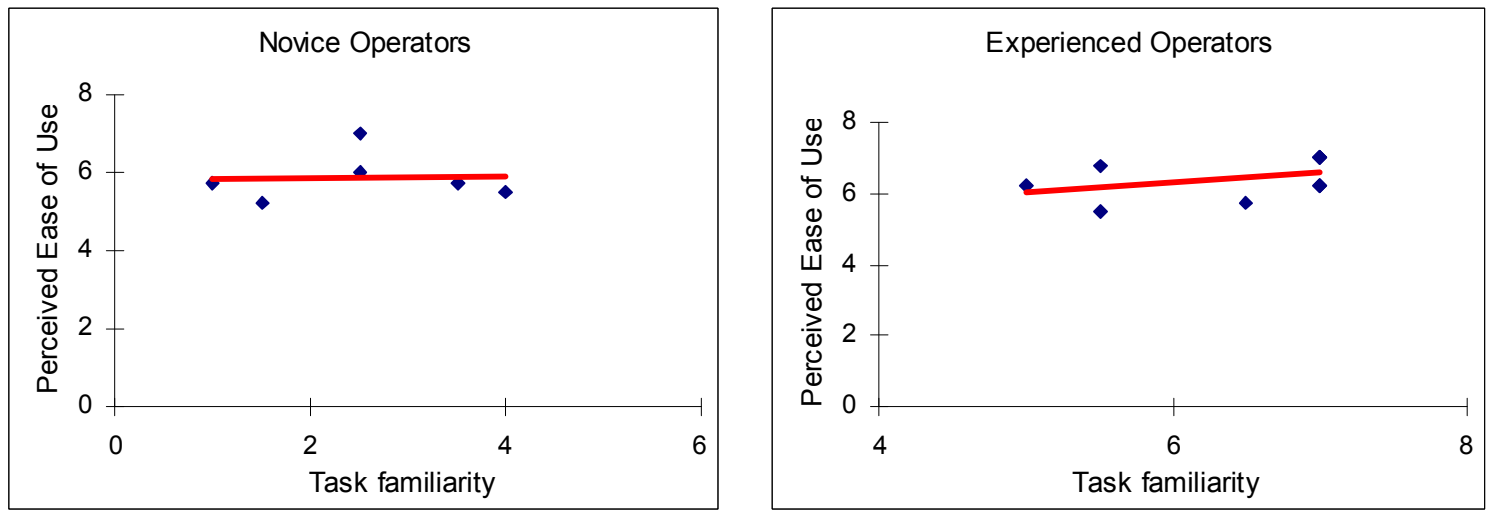

Figure $4 \square$ Impact of task familiarity to perceived ease of use (EOU)
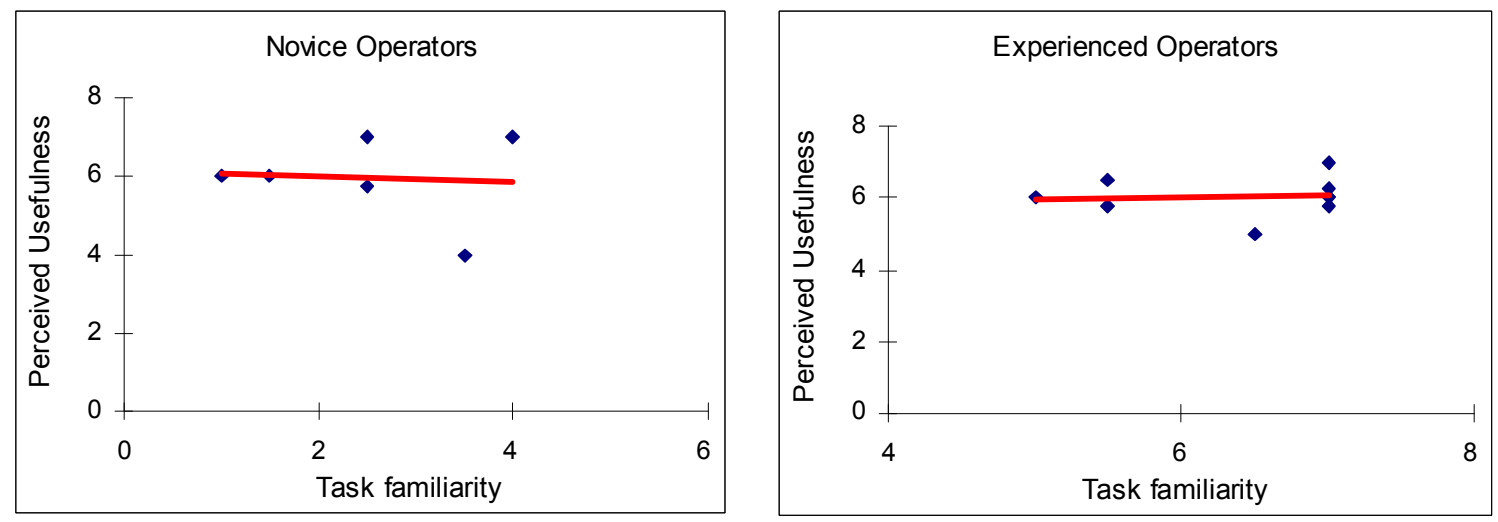

Figure $5 \square$ Impact of task familiarity to perceived usefulness (U) 

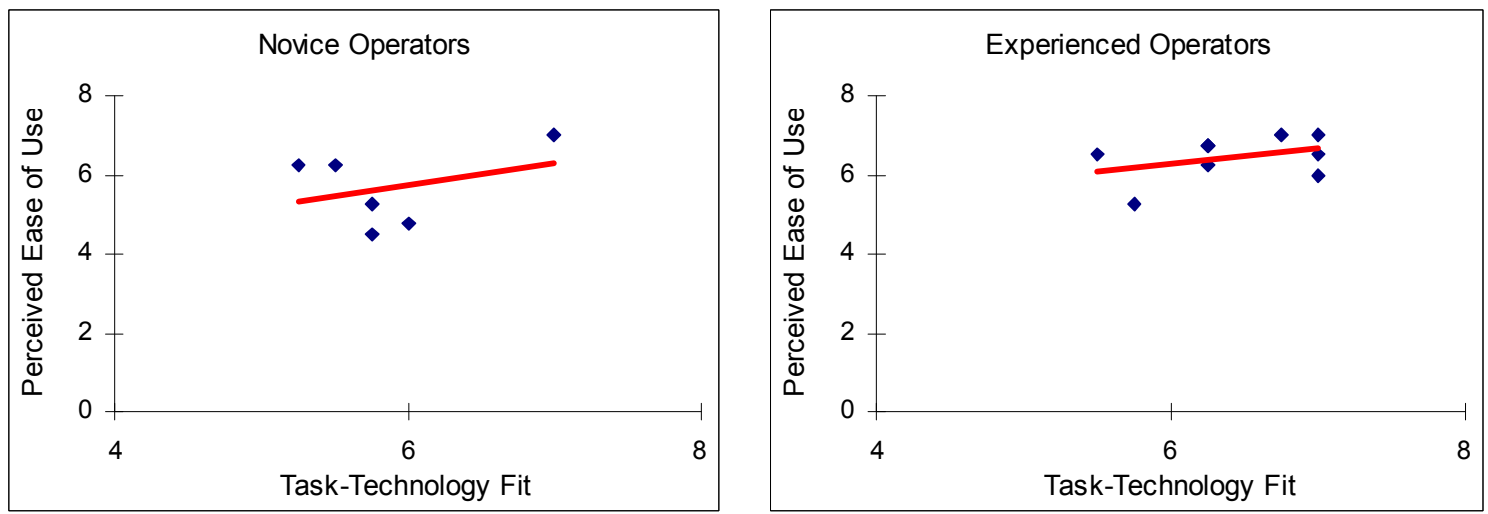

(a)
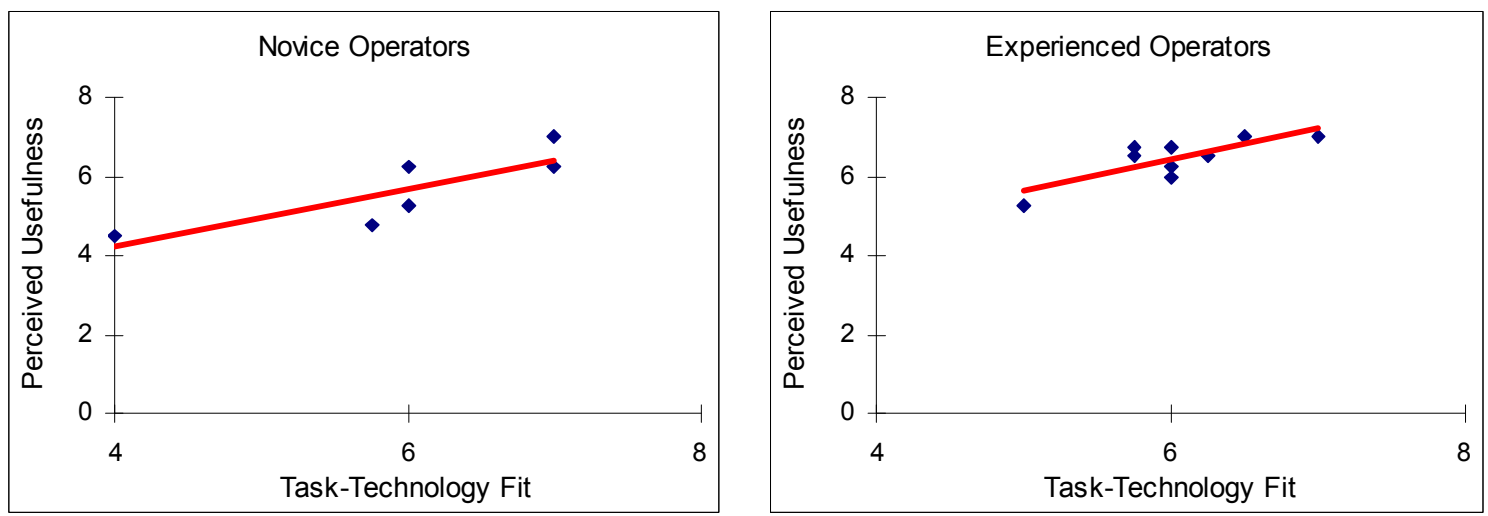

(b)

Figure $6 \square$ Relationships between TTF and Acceptance of the Program 

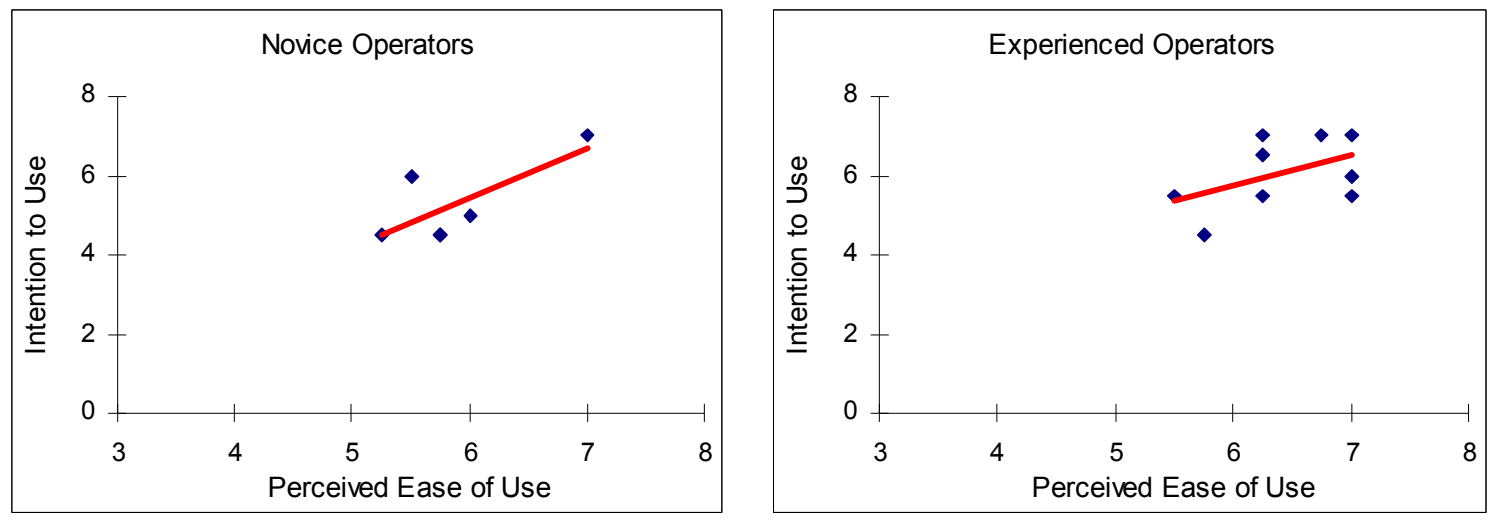

(a)
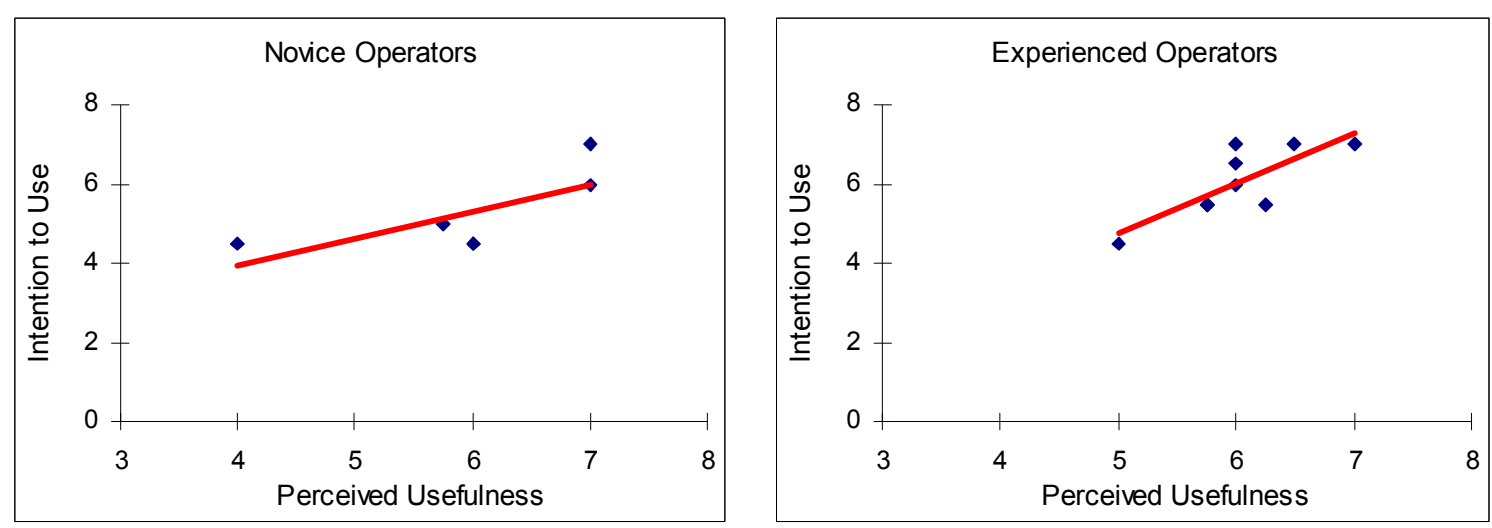

(b)
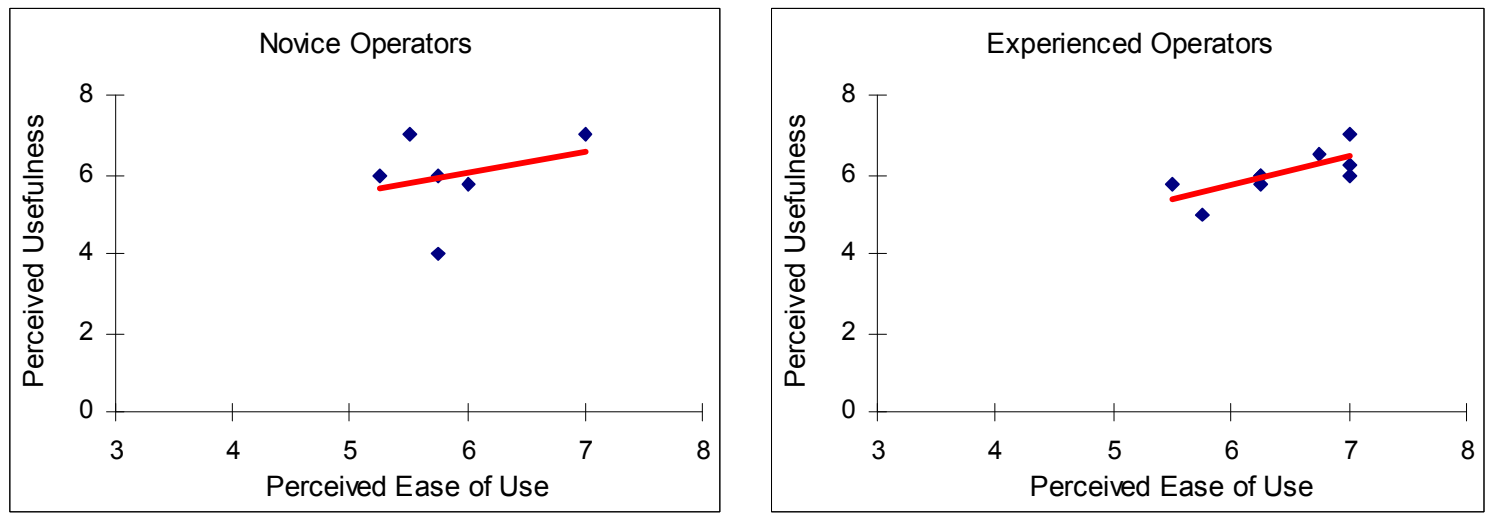

(c)

Figure $7 \square$ Relationships between TAM constructs 
Table $1 \square$ Part 1 of the Questionnaire

\begin{tabular}{|c|c|c|c|c|c|c|}
\hline & & Never & $\begin{array}{l}0-6 \\
\text { months }\end{array}$ & $\begin{array}{l}7-12 \\
\text { months }\end{array}$ & $\begin{array}{l}>12 \\
\text { months }\end{array}$ & $\begin{array}{l}\text { No } \\
\text { longer }\end{array}$ \\
\hline DU & How long have you been working in test area? & & & & & \\
\hline
\end{tabular}

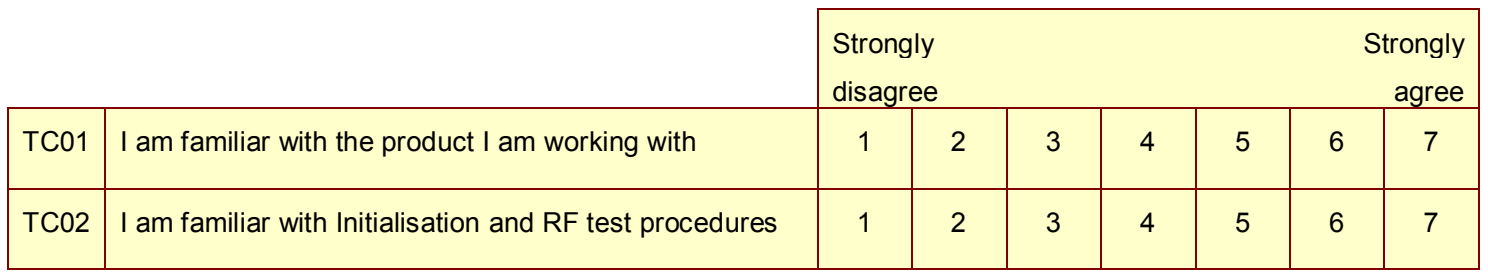

Table $2 \square$ TAM constructs - after [8]

\begin{tabular}{|c|c|c|c|c|c|c|c|c|}
\hline \multirow[b]{2}{*}{ EOU01 } & \multirow{2}{*}{$\begin{array}{l}\text { Items to measure perceived Ease of Use (EOU) } \\
\text { Learning to use the program is easy for me }\end{array}$} & \multicolumn{5}{|c|}{$\begin{array}{l}\text { Strongly } \\
\text { disagree }\end{array}$} & \multicolumn{2}{|c|}{$\begin{array}{r}\text { Strongly } \\
\text { agree }\end{array}$} \\
\hline & & 1 & 2 & 3 & 4 & 5 & 6 & 7 \\
\hline EOU02 & I find it takes a lot of effort to become skilful at using the program* & 1 & 2 & 3 & 4 & 5 & 6 & 7 \\
\hline EOU03 & Interacting with the program is frustrating for $\mathrm{me}^{*}$ & 1 & 2 & 3 & 4 & 5 & 6 & 7 \\
\hline \multirow[t]{2}{*}{ EOU04 } & Overall, I find the program easy to use & 1 & 2 & 3 & 4 & 5 & 6 & 7 \\
\hline & Items to measure perceived Usefulness (U) & & & & & & & \\
\hline U01 & I believe the program will make my job easier to complete & 1 & 2 & 3 & 4 & 5 & 6 & 7 \\
\hline U02 & I think the program will support me to do my job & 1 & 2 & 3 & 4 & 5 & 6 & 7 \\
\hline U03 & I think the program will improve my job performance & 1 & 2 & 3 & 4 & 5 & 6 & 7 \\
\hline \multirow[t]{2}{*}{ U04 } & Overall, I think the program is useful & 1 & 2 & 3 & 4 & 5 & 6 & 7 \\
\hline & Items to measure perceived Intention to Use (IU) & & & & & & & \\
\hline IU01 & I intend to use the program if I have problems & 1 & 2 & 3 & 4 & 5 & 6 & 7 \\
\hline IU02 & I would use and recommend the program to my colleague & 1 & 2 & 3 & 4 & 5 & 6 & 7 \\
\hline
\end{tabular}

* $=$ reverse-coded items 
Table $3 \square$ Constructs dropped due to irrelevant context

\begin{tabular}{|ll|}
\hline Dimension & Definition \\
\hline Locatability & Ease of determining what data is available and where \\
Assistance & Ease of getting help on problems with data \\
Compatibility & Ease with which data from different sources can be compared without inconsistency \\
Lack of confusion & A result of data stored in many forms and places \\
\hline
\end{tabular}

Table $4 \square$ Final TTF constructs employed

\begin{tabular}{|ll|}
\hline Dimension & Definition \\
\hline Accuracy (ACU) & Correctness of the information \\
Currency (CUR) & The most up-to-date information \\
Meaning (MEA) & Ease of determining what the information or data means \\
Accessibility (ACC) & Easy access to desired information \\
System reliability (REL) & Dependability of access and uptime of systems \\
\hline
\end{tabular}

Table $5 \square$ TTF questions $\square$ after [18]

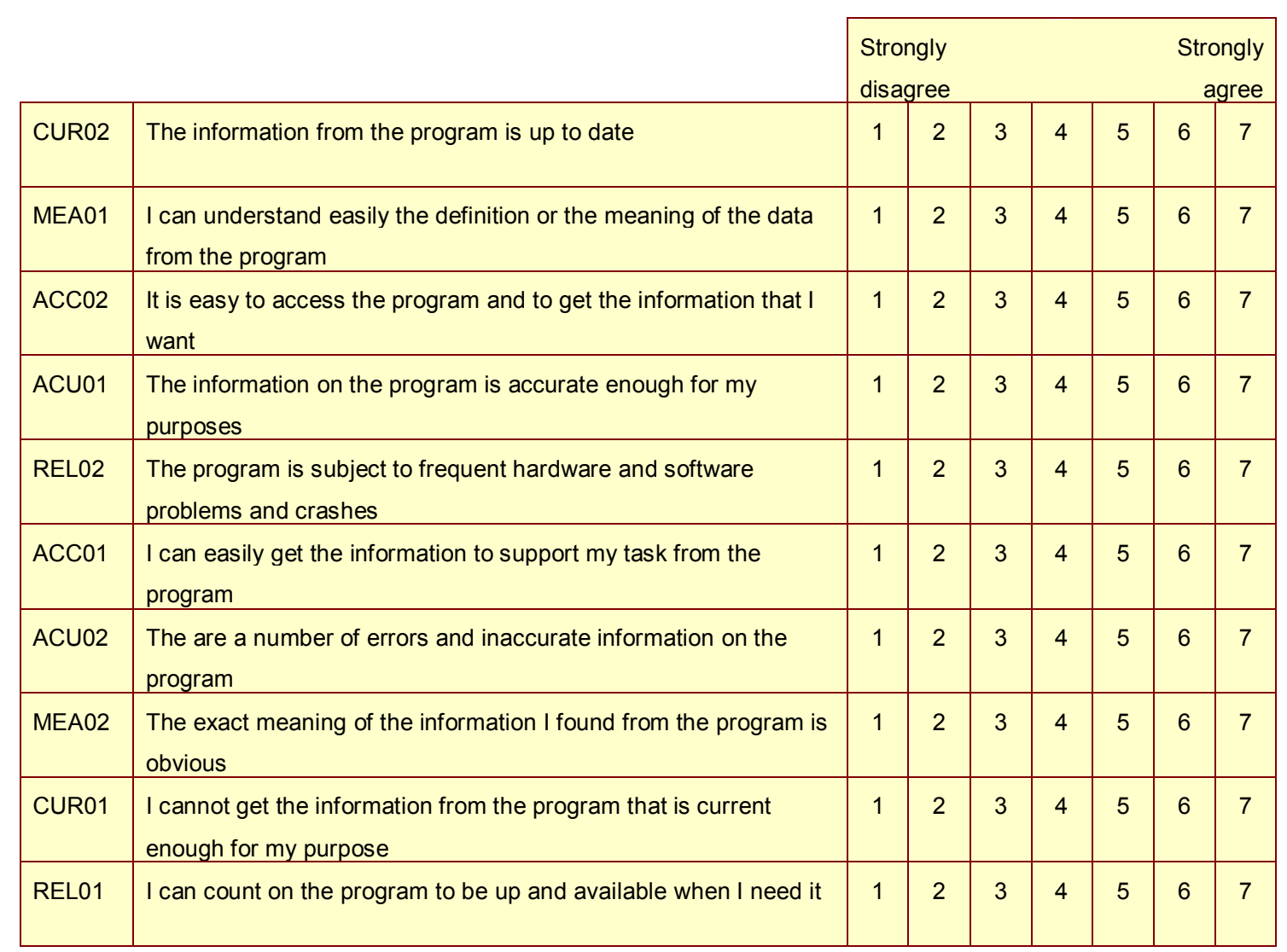


Table $6 \square$ Users $\square$ perception of the program

\begin{tabular}{|l|l|l|l|l|}
\cline { 2 - 5 } \multicolumn{2}{c|}{} & \multicolumn{2}{l|}{ Novice operators } & \multicolumn{2}{l|}{ Experienced operators } \\
\cline { 2 - 5 } & Mean & St Dev & Mean & St Dev \\
\hline Perceived ease of use (EOU) & 5.89 & 0.61 & 6.57 & 0.56 \\
\hline Perceived usefulness (U) & 5.96 & 1.10 & 6.00 & 0.55 \\
\hline Perceived task-technology fit (TTF) & 5.61 & 0.98 & 6.30 & 0.56 \\
\hline Intention to use (IU) & 5.25 & 1.04 & 6.05 & 0.88 \\
\hline
\end{tabular}

